\title{
Lesion Sterilization and Tissue Repair Therapy (LSTR) of Necrotic Primary Molars: Case Report
}

\author{
${ }^{1}$ Hariri El Mehdi, ${ }^{2}$ Chhoul Hakima \\ ${ }^{1}$ Resident in pediatric dentistry, faculty of dentistry, Center of consultation and dental treatment of \\ Rabat, University of Mohammed V Rabat, Morocco. \\ ${ }^{2}$ Professor of Higher Education and Department Head in Pediatric Dentistry, Faculty of Dentistry, \\ Center of dental treatment and consultation of Rabat, University of Mohammed V Rabat, Morocco.
}

*Corresponding Author: Hariri El Mehdi, 1Resident in Pediatric dentistry, faculty of dentistry, Center of consultation and dental treatment of Rabat, University of Mohammed V Rabat, Morocco

\begin{abstract}
Root canal infections are polymicrobial in nature, consisting of both aerobic and anaerobic species. The successful treatment of endodontic infections involves effective eradication of the causative microorganisms during root canal treatment procedures. Residual infection in root canal system has always been an area of penumbra for a treating dentist. Lesion sterilization and tissue repair (LSTR) therapy is an non conventional endodontic treatment procedure that involves non-instrumentation or minimal instrumentation followed by placement of a triple antibiotic paste in a medication cavity created at the orifices of the teeth to disinfect root canal systems. It is evolving as an alternate treatment procedure in primary molars in comparison to conventional root canal treatment. The aim of this article is to present success of a clinical case treated by LSTR after a clinical and radiographic follow-up of 18 months.
\end{abstract}

Keywords: Lesion Sterilization and Tissue Repair, Triple Antibiotic Paste, primary molars.

\section{INTRODUCTION}

Endodontic treatment of necrotic primary teeth is routinely done in dental practices. But the successful treatement is not evident. This often presents a challenging task to the clinician, due to the typical primary tooth morphology (tortuous root canals, presence of multiple accessory canals, ramifications, and ample medullary bone spaces that favor dissemination of infection). In addition to that, obtaining an hermetic seal is difficult due to the lack of apical closure following physiologic root resorption owing to the close proximity of the developing permanent tooth germ to the roots of the primary teeth. A further challenge presented to the dentist in rendering effective endodontic treatment is the behavior management of uncooperative children (1). In 2004, the Cariology Research Unit of Niigata University School of Dentistry in japan has developed the concept of lesion sterilization and tissue repair (LSTR) therapy of necrotic primary molars that employed a mixture of antibacterial drugs (ciprofloxacin, metronidazole, minocycline) for disinfection. Repair of damaged tissues can be expected if lesions are perfectly disinfected

\section{$(2,3)$.}

\section{CASE Report}

This is the case of a 9 years old young boy (A.M) who was been accompanied by his mother to consult the pediatric dentistry department within the dental school in Rabat, and to undergo caries treatment. The anamnesis reported that he was healthy with no medical or surgical history, but revealed unbalanced eating habits and low oral hygiene habits. The clinical examination revealed the presence of molar incisor hypomineralisation (MIH) in the following teeth: 11/21-31/41-16/26 -36/46, and an abcess regarding the 74 .

The radiographic examination showed that the clinically described hypomineralisated lesions are remote from the pulp (Residual Dentin Thickness "RDT" > 1 mm) with the absence of irreversible pulp pathologies. But at the 74, furcation pathology and internal resorption in the mesial canal was observed. The behavior of the young patient was difficult at first of the consultation, and some psychological techniques were adopted to improve his behavior. In this clinical case, the first primary molar (74) was been treated using LSTR after explaining to the 
patient and his mother our procedure and an informed written consent was been taken. After doing a professional Toothbrushing with fluoride toothpaste, Anesthesia for the tooth to be treated was achieved by inferior alveolar nerve block using (2\%) lidocaine hydrochloride with adrenaline $(1: 80,000)$. Isolation was achieved using rubber dam. The cavity was prepared depending on the extent of the lesion. The carious dentin was excavated with the help of a spoon excavator and with a large round bur. Access to the pulp chamber was gained; roof of the pulp chamber was removed, making sure that all overhanging edges were eliminated. Necrotic pulp was removed with a sharp spoon excavator and pulp chamber was thoroughly irrigated with sodium hypochlorite $(2,5 \%)$ and EDTA (20\%) to visualize the orifices clearly. The pulp chamber and root canals were dried using cotton pellets and cone of absorbent papers. The orifices of the canals were enlarged with straight bur to receive the medicament; which was termed as "medication cavity." Then the medication cavity was filled with antibacterial mixture paste. The tooth was then restored with Glass Ionomer cement (GIC) and further reinforced with composite resin. The whole procedure was completed in one visit. Resolution of clinical signs and symptoms was evaluated within a month after the treatment. At every subsequent visit, once in 6 months for a period of 18 moths clinical and radiographic evaluation was done. The treated case was considered clinically and radiographically successful after 18 moths of follow-up because we observed no signs of spontaneous pain, tenderness to percussion, abnormal mobility and no signs of pathology like intraoral and/ or extraoral abscess and a radiolucency decreased compared to preoperative status.

\section{DISCUSSION}

Endodontic management of necrotic primary molars, evidenced by abscess, fistula and loss of alveolar bone is generally complicated. Though several reasons have been cited for this, the main one being root canal morphology of the primary molars which are not suitable for instrumental procedure (3).Bacteria which are present mainly in the root canal system and superficial layer of infected root canal wall may be easily removed by conventional endodontic treatment. But the bacteria, which remain in the deep layers of root canal dentin, may leak out to periapical region and cause complications. Application of antibacterial medication to endodontic lesions is one of the clinical procedures that can be used to sterilize such lesions (4).In this fact, a single antibacterial medication may not be effective, even if it is a large spectrum antibiotic, because bacterial composition of the infected root canals is complex in natural. In addition, bacteria may also invade root canals from other oral sites, like dental biofilm, saliva and from carious dentin which may also smear the root canal during endodontic treatment. All such bacteria should be targeted by specific antibacterial medication. Since the overwhelming majority of bacteria in the deep layers of infected dentine of the root canal wall consist of obligate anaerobes, metronidazole was selected as first choice among the antibacterial drugs. Metronidazole even at high concentrations cannot eradicate all the bacteria indicating the necessity of other drugs (6,7). Thus, ciprofloxacin and minocycline, in addition to metronidazole were added to sterilize infected root dentin. This mixture antibiotics paste should penetrate root canal dentin. The penetration ability of these drugs was improved by mixing these drugs with propylene glycol and macrogol to form ointment base.The penetration ability of propylene glycol was clearly demonstrated by Cruz et al (9).In patients showing internal/external root resorption, physiologic root resorption exceeding 2/3root length requiring short term space management, Lesion Sterilization and Tissue Repair may be considered as an alternative procedure $(10,11)$. This technique may also find application in uncooperative children and in children with special needs in whom conventional endodontic treatment cannot be performed due to associated medical conditions. The procedure has also been used in controlling recurrent/persistent infections without prolonged systemic antibiotic therapy. It may also find application in managing necrotic primary molars in remote areas where access to dental care is poor $(10,15)$. This application of LSTR technique has been researched and reported to be successful.

\section{CONCLUSION}

Through this clinical case, endodontic treatment using antibacterial mix (a combination of ciprofloxacin, metronidazole, and minocycline mixed with propylene glycol and macrogol) in primary molars has shown good clinical and radiographic success. However, we advocate further clinical and histological studies with longer follow-up till the period of tooth exfoliation to ascertain the efficacy of this novel treatment modality. 

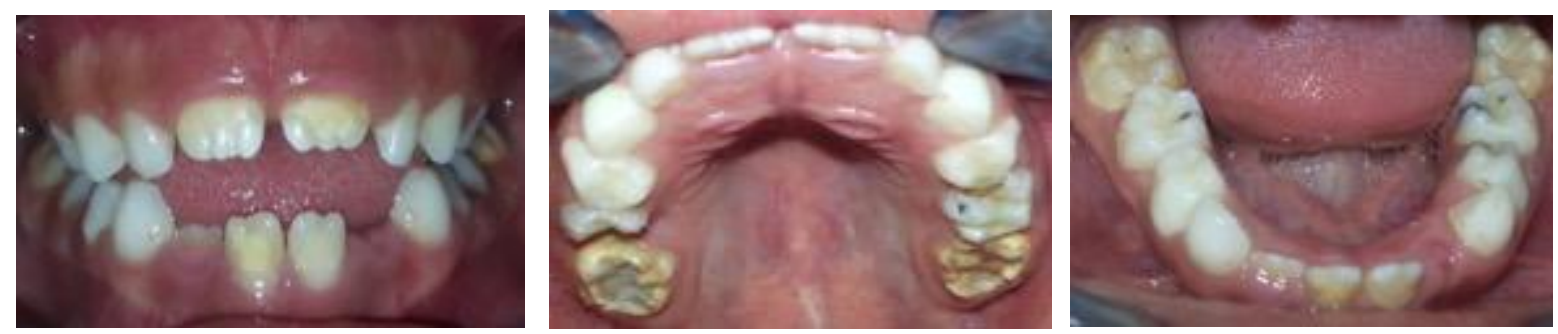

Fig1: Endobuccalview

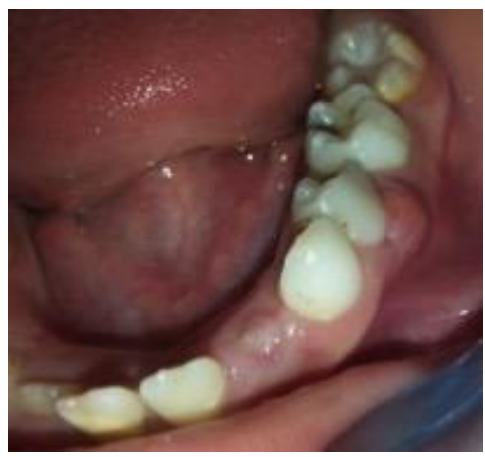

Fig2. Abscess in front of 74

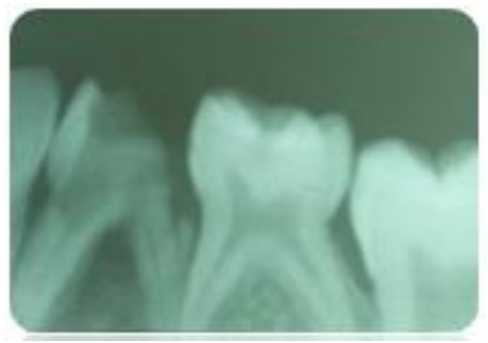

Fig3. Radiolucency atfurcation zone and internalresorption
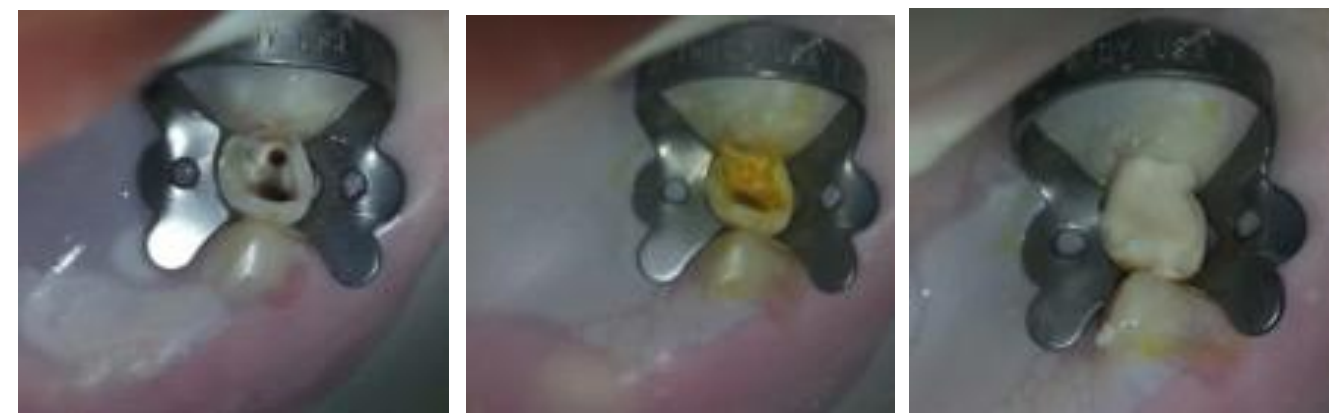

Fig4. Cinicalsteps of the LSTR : medicationcavity, 3Mix and glass ionomer restauration

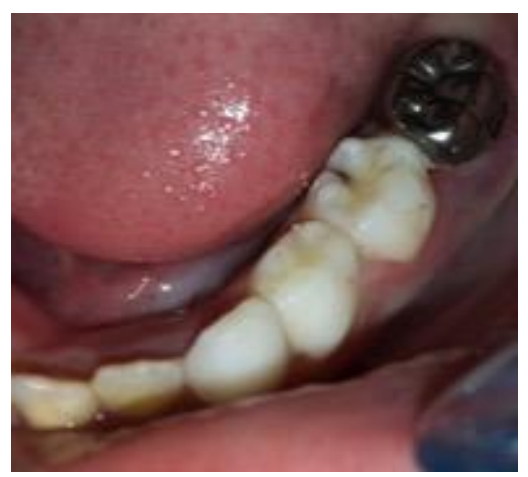

Fig5. Disappearance of the abscess : clinical silence 


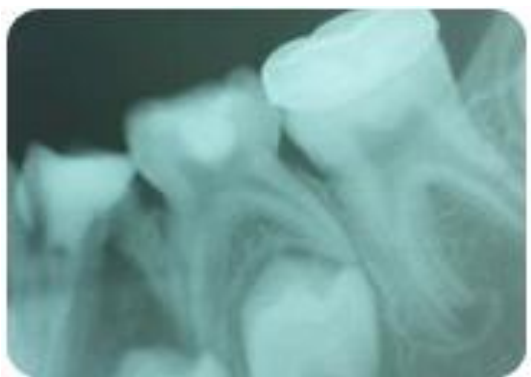

Fig6. Reduction of the radiolucency at furcation zone and alveolarbonerepair

\section{REFERNCES}

[1] Vijayaraghavan R, Mathian VM, Sundaram AM, et al. Triple antibiotic paste in root canal therapy. J Pharm Bioallied Sci. 2012; 4:S230-3.

[2] Hoshino E, Asgor MA, Yagi M, Cruz EV et al. 2044 LSTR 3 Mix-MP NIET in Area Oral Health Program. Under 'Cariology research'. In: Dental material for prevention. Report presented at IADR/AADR/LADR 83rd general session, Baltimore, MD 2005.

[3] Bansal R, Jain A. Overview on the current antibiotic containing agents used in endodontics. N Am J Med Sci. 2014; 6(8):3518.

[4] Ran Yang, Chan Yang, Yuan Liu, Yong Hu, Jing Zou : Evaluate root and canal morphology of primary mandibular second molars in Chinese individuals by using cone-beam computed tomography: Journal of the Formosan Medical Association (2013) 112, $390 \mathrm{e} 395$.

[5] 24. Ozan U, Er K. Endodontic treatment of a large cyst- like periradicular lesion using a combination of antibiotic drugs: a case report. J Endod. 2005; 31(12):898-900.

[6] Takushige T, Cruz EV, Moral AA, Hoshino E. Endodontic treatment of primary teeth using a combination of antibacterial drugs. Int Endod $\mathbf{J}$ 2004; 37:132-8.

[7] de Sousa EL, Ferraz CC, Gomes BP, Pinheiro ET, Teixeira FB, de Souza-Filho FJ. Bacteriological study of root canals associated with periapical abscess. Oral Surg Oral Med Oral Pathol Oral Radiol Endod 2003; 96:332-9.
[8] Guidelines on appropriate use of antibiotic therapy for pediatric dental patients. AAPD reference manual 2007/08; 29:199-201.

[9] Lesion sterilization and tissue repair technique. Available at: www.pediatricdentistry. com. Ph / PPDSI/LSTR.puff. Accessed 21 Jan 2009.

[10] Alam T, Nakazawa F, Nakajo K, Uematsu H, Hoshino E. Sus- ceptibility of enterococcus faecalis to a combination of antibacterial drugs (3mix) in vitro. J Oral Biosci 2005; 47:315-320.

[11] Hoshino E, Asgor MA, Yagi M, Garcia EV. 1786 Oral health program using LSTR 3mixMP NIET therapy. at: http://iadr.confex.com/iadr/2006Orld/techprogr am/abstract 73714.htm. Accessed 22 Nov 2008.

[12] Takushige T, Cruz EV, Moral AA, Hoshino E. Endodontic treatment of primary teeth using a combination of antibac- terial drugs. Int Endod J 2004; 37:132-138.

[13] Del Pozo PP, Soto MJB, Troisfontaines ESE. Antibiotic prophylaxis in pediatric odontology: an update. Med Oral Patol Oral Cir Bucal 2006; 11:E352-357.

[14] Keenan JV, Farman AG, Fedorowicz Z, Newton JT. A Cochrane systematic review finds no evidence to support the use of antibiotics for pain relief in irreversible pulpitis. J Endod 2006; 32:87-92.

[15] Baumgartner JC, Bakland LK, Sugita EI. Microbiology of endodontics and asepsis in endodontic practice. In: Ingle JI and Bakland LK (eds). Endodontics, ed 5. Hamilton, ON: BC Decker 2002:74-79.

Citation: Hariri E, Chhoul H. Lesion Sterilization and Tissue Repair Therapy (LSTR) of Necrotic Primary Molars: Case Report. International Journal of Research Studies in Medical and Health Sciences. 2017;2(4):1-4.

Copyright: (c) 2017 Hariri E \& Chhoul H. This is an open-access article distributed under the terms of the Creative Commons Attribution License, which permits unrestricted use, distribution, and reproduction in any medium, provided the original author and source are credited. 